\title{
Studies on regional cerebral oxygen utilisation and cognitive function in multiple sclerosis
}

\author{
DJ BROOKS, ${ }^{*} \dagger$ KL LEENDERS, ${ }^{*}$ G HEAD, J MARSHALL, $\dagger$ NJ LEGG,§ T JONES* \\ From the MRC Cyclotron Unit, Hammersmith Hospital, ${ }^{*}$ Institute of Neurology, Queen Square, $\dagger$ Department \\ of Clinical Psychology, Friern Hospital, $\ddagger$ and the Department of Medicine (Neurology), Hammersmith \\ Hospital, § London, UK
}

SUMMARY Regional cerebral oxygen utilisation $\left(\mathrm{rCMRO}_{2}\right)$, oxygen extraction ( $\left.\mathrm{rOER}\right)$, blood flow (rCBF), and blood volume (rCBV) have been determined for fifteen patients with multiple sclerosis in remission using positron emission tomography (PET). Cerebral oxygen utilisation and blood flow were significantly reduced in both white matter and peripheral cortical grey matter in the multiple sclerosis patients compared to a group of normal controls. No evidence of regional cerebral ischaemia in the multiple sclerosis group was found. Lowest levels of cerebral oxygen utilisation were found in patients with cerebral atrophy, and in patients in whom a significant fall in present full-scale IQ from estimated pre-morbid levels had occurred. No correlation was found between $\mathrm{rCMRO}_{2}$ values and severity of locomotor dysfunction or clinical disease duration.

The primary pathology of multiple sclerosis consists of plaques of demyelination distributed about the central nervous system. ${ }^{12}$ These plaques range from $1 \mathrm{~mm}-4 \mathrm{~cm}$ in size and initially form as perivenular sleeves of demyelination. ${ }^{3}$ The lesions contain macrophages, lymphocytes and plasma cells and characteristically consist of breakdown of the myelin sheath with axonal sparing. ${ }^{4}$ Occasionally Wallerian degeneration of the axon is seen. The plaques tend to be symmetrically distributed with a prediliction for the spinal cord, cerebellum, and periventricular regions. At necropsy, however, numerous plaques may be found in clinically silent areas of central white and cortical grey matter. ${ }^{5}$

Gyldensted has reviewed $110 \mathrm{CT}$ brain scans of multiple sclerosis patients and found a $36 \%$ incidence of intracerebral plaques and a $79 \%$ incidence of generalised central white matter atrophy and/or widening of the cortical sulci. ${ }^{6}$ Forty five per cent of his group had evidence of generalised cerebral atrophy in the absence of demonstrable focal plaques. It is likely that a higher incidence of plaques would have been found had brain scans been performed with a nuclear magnetic resonance (NMR) rather than a CT scanner. ${ }^{78}$

Address for reprint requests: Dr DJ Brooks, MRC Cyclotron Unit, Hammersmith Hospital, London W12 0HS, UK.

Received 13 April 1984

Accepted 5 May 1984
A number of studies have been carried out on levels of cognitive function in multiple sclerosis. Peyser et al $^{9}$ studied 55 multiple sclerosis patients and found a $55 \%$ incidence of impaired cognitive function. Impairment of general cognitive function correlated significantly with clinical disease duration but not with the degree of neurological disability. Several studies have shown a selective impairment of performance IQ relative to verbal IQ in multiple sclerosis. ${ }^{10-12}$ Jambor $^{13}$ has examined cognitive function of specific cortical regions in a group of 103 multiple sclerosis patients and again demonstrated a significant impairment. None of these studies however compared CT brain scan findings with levels of cognitive function.

Claims have been made for the efficiency of hyperbaric oxygen in ameliorating symptoms of multiple sclerosis. ${ }^{14}$ is In one of these studies, ${ }^{15}$ a double-blind controlled study, significant though transient improvements in mobility, fatigability, and balance were noted in patients treated with hyperbaric oxygen compared to those given a placebo. The mechanism of action of hyperbaric oxygen is uncertain. One possibility is that it acts as an immunosuppressive agent. ${ }^{1617}$ A second possibility that has been suggested ${ }^{15}$ is that regions of ischaemia exist in perivenular plaques due to an associated venous back pressure, and that such ischaemia is transiently relieved by hyperbaric oxygen.

The purpose of this study was two-fold. Firstly, we 
Table 1 Clinical details of multiple sclerosis patients

\begin{tabular}{|c|c|c|c|c|c|c|}
\hline Patient & Age at onset & $\begin{array}{l}\text { Disease } \\
\text { duration (yr) }\end{array}$ & $\begin{array}{l}\text { Locomotor } \\
\text { dysfunction }\end{array}$ & $M S^{18}$ classification & $C S F$ & $V E P$ latency \\
\hline $\begin{array}{r}1 \\
2 \\
3 \\
4 \\
5 \\
6 \\
7 \\
8 \\
9 \\
10 \\
11 \\
12 \\
13 \\
14 \\
15\end{array}$ & $\begin{array}{l}34 \\
35 \\
26 \\
17 \\
40 \\
29 \\
53 \\
32 \\
30 \\
34 \\
20 \\
33 \\
29 \\
47 \\
24\end{array}$ & $\begin{array}{r}24 \\
3 \\
28 \\
3 \\
14 \\
15 \\
14 \\
4 \\
18 \\
16 \\
6 \\
14 \\
8 \\
7 \\
3\end{array}$ & $\begin{array}{l}+ \\
+ \\
+ \\
+ \\
++ \\
+ \\
++ \\
+ \\
++ \\
+ \\
++ \\
++ \\
+ \\
+ \\
++\end{array}$ & $\begin{array}{l}\text { CDMS A1 } \\
\text { CDMS A1 } \\
\text { CDMS A2 } \\
\text { LSDMS B1 } \\
\text { LSDMS B1 } \\
\text { CDMS A1 } \\
\text { CDMS A1 } \\
\text { CDMS A2 } \\
\text { CDMS A1 } \\
\text { CDMS A1 } \\
\text { CDMS A1 } \\
\text { CDMS A1 } \\
\text { LSDMS B1 } \\
\text { LSDMS B1 } \\
\text { CDMS A1 }\end{array}$ & $\begin{array}{l}\overline{-} \\
\overline{\text { OB }} \\
\text { OB } \\
\text { IgG } \uparrow \\
\text { IgG } \uparrow \\
\text { Normal } \\
\overline{\text { Paretic }} \\
\text { IgG } \uparrow \\
\text { OB } \\
\text { OB } \\
\text { OB } \\
\text { IgG } \uparrow \\
\text { OB }\end{array}$ & $\begin{array}{l}\bar{Z} \\
\uparrow \\
\frac{\uparrow}{\uparrow} \\
\frac{1}{\text { Normal }} \\
\uparrow \\
\frac{\uparrow}{\uparrow}\end{array}$ \\
\hline Mean & 32 & 12 & & & & \\
\hline
\end{tabular}

$\mathrm{OB}=$ Oligoclonal bands. Paretic $=$ Paretic Lange curve. $\mathrm{IgG} \uparrow=$ IgG: protein ratio $>13 \% . \uparrow=$ prolonged VEP latency. $\mathrm{CDMS}=\mathrm{Clinical}$ definite multiple sclerosis. LSDMS = Laboratory supported multiple sclerosis.

wished to measure levels of cerebral oxygen utilisation in multiple sclerosis and to correlate these with neurological and cognitive function, and the presence of cerebral atrophy. Secondly we wished to investigate whether a rationale exists on metabolic grounds for raising the level of the oxygen content of arterial blood supplying the cerebral tissues of multiple sclerosis patients by administering hyperbaric oxygen.

\section{Methods and patient selection}

The fifteen multiple sclerosis patients selected for this study had either clinically definite (CDMS) or laboratorysupported definite (LSDMS) multiple sclerosis according to criteria recently laid down. ${ }^{18}$ Clinical details of the fifteen patients studied are shown in table 1 .

Age of clinical onset of disease ranged from 17-53 years and clinical disease duration from 3-28 years. All patients studied had evidence of spasticity on clinical examination. Severity of locomotor dysfunction was graded $(+)$ if the patient could walk without aids, and $(++)$ if crutches or a wheelchair were required for locomotion.

The cerbrospinal fluid (CSF) was examined in twelve patients. In eleven of these the CSF was abnormal with either oligoclonal banding on immunoelectrophoresis, a paretic Lange curve, or an IgG:total protein ratio greater than $13 \%$. Seven out of nine patients who had their visual

Table 2 A comparison of age range, arterial oxygen content, haemoglobin and $\mathrm{pCO} \mathrm{O}_{2}$ between the multiple sclerosis and normal control groups

\begin{tabular}{lcc}
\hline & $\begin{array}{l}\text { Multiple sclerosis (15) } \\
\text { mean } \pm S D\end{array}$ & $\begin{array}{c}\text { Normals (13) } \\
\text { mean } \pm S D\end{array}$ \\
\hline $\begin{array}{l}\text { Age } \\
\text { Haemoglobin }(\mathrm{g} / \mathrm{dl})\end{array}$ & $\begin{array}{c}44 \pm 13 \\
\text { Arterial oxygen }\end{array}$ & $39 \pm 11$ \\
content $\left(\mathrm{mls} \mathrm{O}_{2} / \mathrm{ml}\right)$ & $0 \cdot 19 \pm 0.016$ & $13 \cdot 3 \pm 1 \cdot 2$ \\
Arterial $\mathrm{pCO}_{2}(\mathrm{kPa})$ & $5 \cdot 2 \pm 0.48$ & $0 \cdot 18 \pm 0.016$ \\
\hline
\end{tabular}

evoked potentials (VEPs) assessed had prolonged latencies of these in one or both eyes.

Thirteen of the fifteen patients had CT brain scans performed as part of this study. The presence or absence of plaques and cerebral atrophy was decided by a panel of neuroradiologists from the National Hospital for Nervous Diseases, London, UK, with a prior knowledge of the patients' ages but not of their clinical condition.

Psychometric tests of general and specific cognitive function were carried out on thirteen of the fifteen patients by a clinical psychologist $(\mathrm{GH})$ who had no prior knowledge of the results of clinical examination or physical investigations. Present IQ (post-morbid IQ) was assessed with seven sub-tests of the Wechsler Adult Intelligent Scale (WAIS): ${ }^{19}$ Arithmetic, Similarities, Digit Span, Vocabulary, Picture Completion, Block Design, and Picture Arrangement. One patient (GL) was physically unable to perform the Block Design subtest and in his case the IQ was prorated from six sub-tests. Pre-morbid IQ was estimated from combined scores on the National Adult Reading Test (NART) and Schonell Graded Word Reading Test $^{20}{ }^{30}$ which were standardised against those WAIS subtests listed above. Tests of specific functions listed below were also administered. Verbal and visual memory (forced-choice recognition of words and faces), object recognition (unusual views test), visual perception (fragmented letters test) are as described by McKenna and Pratt. ${ }^{21}$ Frontal function was sampled with a work-fluency test (number of words beginning with $S$ produced by the patient in two minutes-see Benton ${ }^{22}$ ), the Weigl Colour Form Sorting Test, ${ }^{23}$ and a tapping test to examine verbal control of motor acts. ${ }^{24}$

Scores were classified as abnormal if they fell below the 5th percentile for normal subjects. A fall in present fullscale IQ of twelve points or greater from estimated premorbid levels was taken as a significant deterioration, as such a discrepancy was found in $4 \%$ only of normal subjects.

The thirteen normal controls selected for this study (eight males and five females) were healthy, normotensive volunteers with ages ranging from $26-63$ years. Table 2 
compares ages, haemoglobin levels, arterial $\mathrm{pCO}_{2}$ levels, and arterial oxygen contents of the multiple sclerosis and normal control groups. No differences between the groups were found.

Regional cerebral blood flow and oxygen extraction were measured using positron emission tomography during steady-state inhalation of $\mathrm{C}^{15} \mathrm{O}_{2}$ and ${ }^{15} \mathrm{O}_{2}$, an EG and $\mathrm{G}$ Ortec ECAT II scanner with a full-width-half-maximum height (FWHM) resolution of $17 \mathrm{~mm}$ being employed.25 Corrections for the tissue attenuation of $511 \mathrm{keV}$ q-irradiation were carried out by obtaining transmission scans at the same axial tomographic level as emission scans using a ${ }^{68} \mathrm{Ge}$ ring source as previously described. ${ }^{25}$ Arterial plasma and whole-blood ${ }^{15} \mathrm{O}$ concentrations were measured during PET scanning by withdrawing multiple arterial samples via an indwelling 22-gauge teflon radial artery cannula, and well-counting. These data, combined with the regional tissue concentrations of ${ }^{15} \mathrm{O}$ measured using PET scanning, enabled absolute values of rCBF and rOER to be obtained from tracer equations. ${ }^{25} \mathrm{rCMRO}_{2}$ values were derived from values of $\mathrm{rCBF}$, rOER, and the oxygen content of arterial blood using the relationship:

$\mathrm{rCMRO}_{2}=\mathrm{rCBF} \times$ rOER $\times$ arterial oxygen content

Regional cerebral blood volume (rCBV) was measured by labelling red cells via inhalation of " $\mathrm{CO}$ as detailed by Phelps et al. ${ }^{26}$ This information was used to correct for errors in rOER and $\mathrm{rCMRO}_{2}$ measurements arising from the superimposition of signal from ${ }^{15} \mathrm{O}$ contained within the cerebral blood pool onto the metabolic ${ }^{15} \mathrm{O}$ signal due to uptake of tracer by cerebral tissue. ${ }^{27}$ Patients and normal controls were scanned with the single-slice ECAT II PET scanner so as to produce transaxial tomographic images $2.5 \mathrm{cms}$ and $6.5 \mathrm{cms}$ above the orbitomeatal line $(\mathrm{OM}+2 \cdot 5, \mathrm{OM}+6 \cdot 5)$. These tomographic planes correspond to the level of the cerebellum, and the top of the lateral ventricles and centrum semiovale respectively.

The purpose and nature of this study was approved by the Hammersmith Hospital Research Ethics Committee, London. The United Kingdom Administration of Radioactive Substances Advisory Committee has given permission for the administration of radioisotopes to perform these studies. The informed consent of the patient was obtained prior to the commencement of each study.

\section{Data Analysis}

Measurements of blood flow and oxygen consumption in cerebral white matter were taken from the left and right centrum semiovale at an axial tomographic level of $\mathrm{OM}+$ $6.5 \mathrm{~cm}$. Regions of white matter clear of lateral ventricle were identified by overlaying patient $\mathrm{CT}$ brain scan images at an equivalent tomographic level onto the $\mathrm{rCMRO}_{2}$ image for each subject. Two circular regions of interest (ROIs) radius $1 \mathrm{~cm}$ containing $49-2.5 \mathrm{~mm} \times 2.5 \mathrm{~mm}$ pixels were used to sample white matter function in each centrum semiovale. The precise locations of these circular ROIs were defined by selecting the regions of white matter from the $\mathrm{rCMRO}_{2}$ image which gave the minimum standard deviation between individual pixel readings for $\mathrm{rCMRO}_{2}$ within the circular ROIs. In this way the homogeneity of the white matter being sampled was maximised. ${ }^{25}$ The average of the mean pixel readings for $\mathrm{rCMRO}_{2}$ in the two
ROIs representing white matter in the left and right centrum semiovale was then taken as the overall mean value for white matter $\mathrm{rCMRO}_{2}$. These two white matter ROI positions defined from the $\mathrm{rCMRO}_{2}$ image were stored and superimposed on rCBF, rCBF and $\mathrm{rCBV}$ images to provide mean white matter values of these variables.

Peripheral cortical grey matter blood flow and oxygen consumption were measured using a cortical plot technique. $^{28}$ Rectangular ROIs $1.5 \mathrm{~cm} \times 0.75 \mathrm{~cm}$ containing 18 pixels were arranged contiguously around the peripheral ribbon of high oxygen utilisation evident on the $\mathrm{rCMRO}_{2}$ image at a level of $\mathrm{OM}+6.5 \mathrm{~cm}$ so as to produce the minimum standard deviation between individual pixel readings. In this way the homogeneity of the cortical tissue being sampled was maximised. Cortical plots prepared in this way contained approximately 900 pixels, and the mean pixel value for $\mathrm{rCMRO}_{2}$ was taken as representing the $\mathrm{rCMRO}_{2}$ value for peripheral grey matter at $\mathrm{OM}+$ $6.5 \mathrm{~cm}$. The positions of the rectangular ROIs comprising the cortical plot as defined on the $\mathrm{rCMRO}_{2}$ image were stored and superimposed on the rCBF, rOER and rCBV images to obtain mean peripheral grey matter values for these variables.

Blood flow and oxygen consumption in the cerebellum were measured at a level of $\mathrm{OM}+2.5 \mathrm{~cm}$. The $\mathrm{rCMRO}_{2}$ image at this level shows regions of high oxygen utilisation corresponding to cerebellar cortex and denate nuclei. An elliptical ROI containing 267 pixels was positioned over cerebellar territory on the $\mathrm{rCMRO}_{2}$ image so as to produce a maximum mean $\mathrm{CCMRO}_{2}$ value per pixel. The position of this elliptical ROI representing cerebellar function as defined from the $\mathrm{rCMRO}_{2}$ image was then stored and superimposed on rCBF, rOER and rCBV scans at OM + $2.5 \mathrm{~cm}$ to provide mean cerebellar values of these variables.

\section{Results}

The clinical details of the fifteen multiple sclerosis patients studied are shown in table 1 . Locomotor dysfunction was graded as outlined in the Methods section. Figure 1 shows similarly scaled PET images of cerebral function at $\mathrm{OM}+6.5 \mathrm{~cm}$ for a patient and a normal control. At this level a perpheral rim of high oxygen utilisation and blood flow is evident, corresponding to peripheral cortical grey matter, with lower $\mathrm{ICMRO}_{2}$ and $\mathrm{rCBF}$ values being seen for the white matter in the left and right centrum semiovale. Figure 2 shows the CT brain scan of the patient, generalised cerebral atrophy and periventricular lucencies being present. Compared to the PET images of the normal subject, those of the patient show a generalised coupled reduction in both cerebral oxygen utilisation and blood flow. The oxygen extraction image of the patient is uniform and similar to the rOER image of the normal subject, both yielding mean rOER values of around $40 \%$ for central white and peripheral grey matter. Regions of ischaemic tissue in which blood flow is 

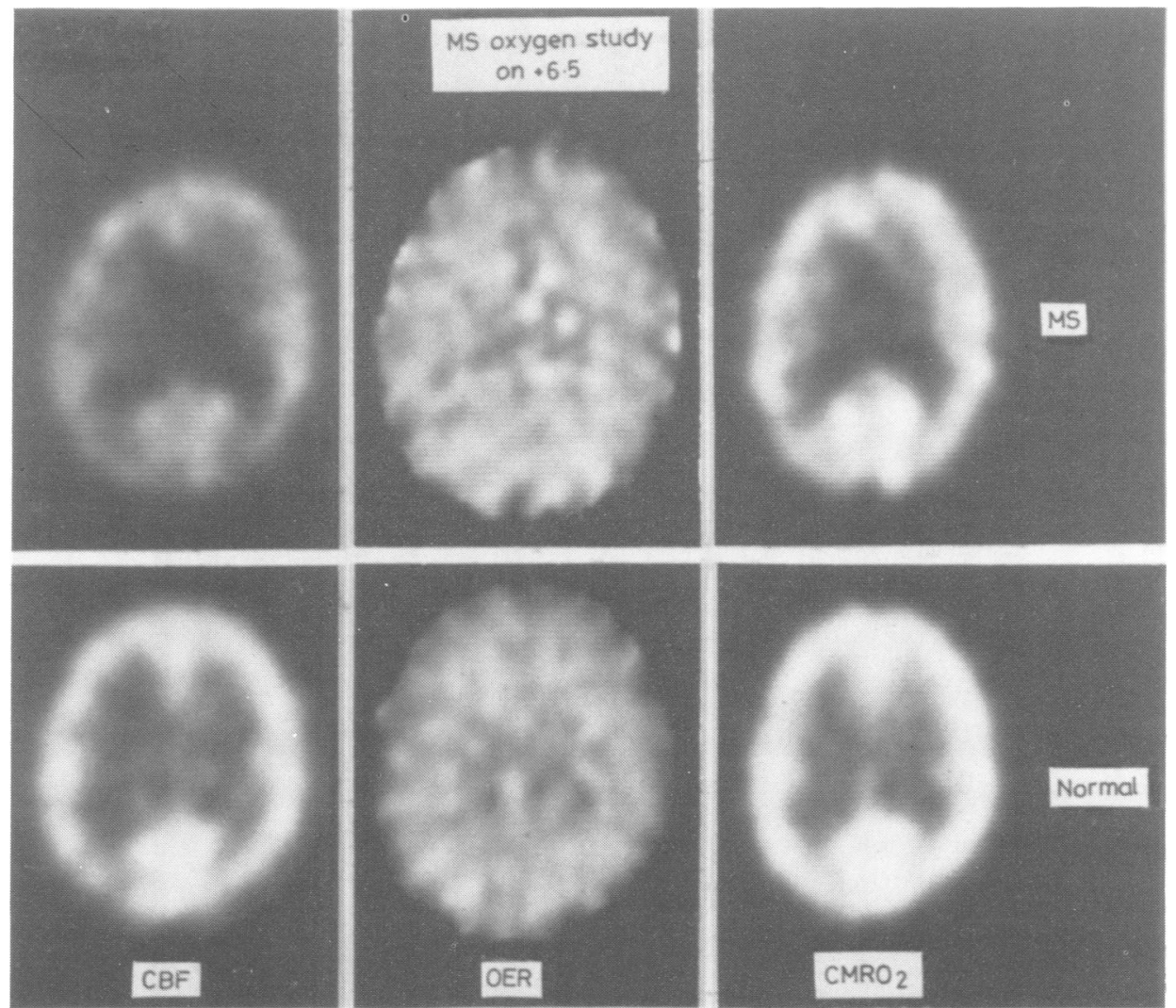

Fig 1 PET images of regional cerebral blood flow, oxygen extraction fraction and oxygen utilisation for a multiple sclerosis patient and normal control.

inappropriately low in relation to cerebral metabolic demands are characterised by high fractional oxygen extractions..$^{28}$ No such regions with raised rOER can be seen in the multiple sclerosis OER image, cerebral blood flow being coupled to cerebral oxygen utilisation in all areas.

Tables 3 and 4 detail respectively the mean white and peripheral cortical grey matter values of $\mathrm{rCBF}$, rOER, rCMRO ${ }_{2}$ and rCBV for the group of fifteen multiple sclerosis patients and thirteen age-matched normal controls. Using an unpaired $t$ test to compare the two groups, the multiple sclerosis group was found to have significantly lower mean $\mathrm{rCMRO}_{2}$ and $\mathrm{CCBF}$ values for both white and peripheral grey matter compared to the normal controls. Mean white and grey matter oxygen extraction however were similar for both groups, no regions of ischaemic tissue with raised oxygen extraction being found in the multiple sclerosis group.
Figure 3 shows the correlation between mean white and peripheral grey matter $\mathrm{rCMRO}_{2}$ in the combined group of individual patients and normal controls. A reduction in oxygen utilisation by both white and grey matter of patients compared to white and grey matter of normal controls is evident. The relationship between mean grey and white matter oxygen utilisation however remains similar for both groups of subjects, stressing the coupled nature of the $\mathrm{rCMRO}_{2}$ reduction in the white and grey matter of the multiple sclerosis group.

Cerebellar oxygen consumption appeared to be little affected in the multiple sclerosis group. Table 5 shows that although mean rCBF was significantly lower for the cerebellum in the multiple sclerosis group, this was balanced by a slight rise in mean rOER. Mean cerebellar oxygen utilisation, while lower for the multiple sclerosis group, did not significantly differ between the two groups at a $5 \%$ 

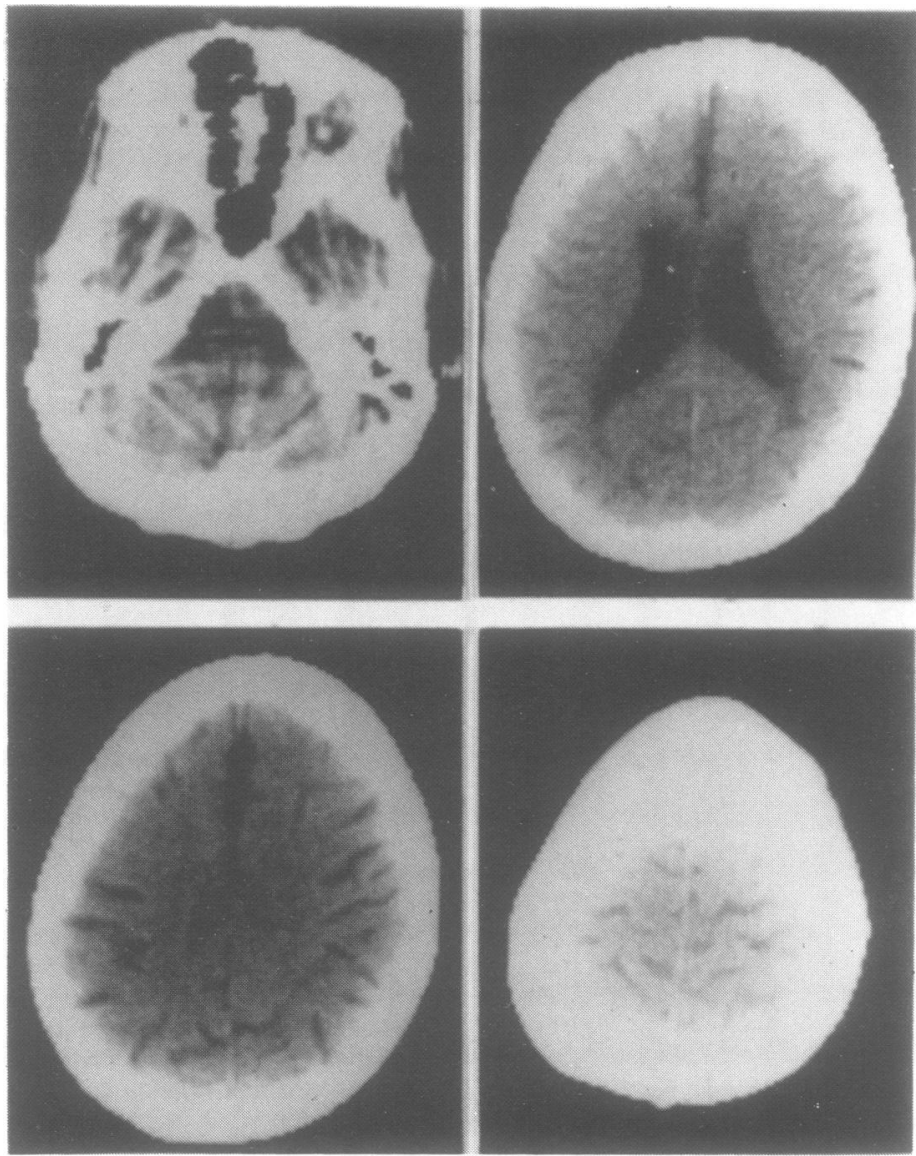

Fig 2 CT Scan of the patient with multiple sclerosis whose PET images are shown in fig 1 .

level of significance.

Of the thirteen patients who had CT brain scans performed as part of this study, eight $(62 \%)$ had evidence of either generalised central white matter and peripheral grey matter atrophy, or generalised white matter atrophy alone-see table 6 . Four of these eight also had evidence of plaques. Figure 4

Table 3 White matter function in multiple sclerosis

\begin{tabular}{|c|c|c|c|}
\hline & $\begin{array}{l}\text { Multiple } \\
\text { sclerosis (15) } \\
\text { mean } \pm S D\end{array}$ & $\begin{array}{l}\text { Normals (13) } \\
\text { mean } \pm S D\end{array}$ & $p$ value \\
\hline $\begin{array}{l}\text { rCBF } \\
\text { (mls/100 } \mathrm{ml} / \mathrm{min}) \\
\text { rOER } \\
\text { rCMRO }\end{array}$ & $\begin{array}{c}21 \pm 4 \\
0.39 \pm 0.07\end{array}$ & $\begin{aligned} 27 & \pm 5 \\
0.38 & \pm 0.06\end{aligned}$ & $\begin{array}{l}<0.05 \\
\text { NS }\end{array}$ \\
\hline $\begin{array}{l}(\mathrm{mls} \mathrm{O} / 100 \mathrm{ml} / \mathrm{min}) \\
\mathrm{rCBV}(\mathrm{mls} / 100 \mathrm{ml})\end{array}$ & $\begin{array}{l}1.4 \pm 0.3 \\
2.7 \pm 0.4\end{array}$ & $\begin{array}{l}1 \cdot 8 \pm 0.2 \\
2.4 \pm 0.8\end{array}$ & $\begin{array}{l}<0 \cdot 01 \\
\text { NS }\end{array}$ \\
\hline
\end{tabular}

NS $=$ Non-significant shows a comparison of mean $\mathrm{rCMRO}_{2}$ for grey and white matter of individual normals, multiple sclerosis patients with cerebral atrophy, and multiple sclerosis patients with normal CT scans. Using an unpaired $t$ test to compare the groups, both grey and white matter $\mathrm{rCMRO}_{2}$ were found to be significantly reduced in the multiple sclerosis atro-

Table 4 Cortical grey matter function in multiple sclerosis

\begin{tabular}{lccl}
\hline & $\begin{array}{l}\text { Multiple } \\
\text { sclerosis (15) } \\
\text { mean } \pm S D\end{array}$ & $\begin{array}{l}\text { Normals (13) } \\
\text { mean } \pm S D\end{array}$ & p value \\
\hline rCBF & $38 \pm 5$ & $45 \pm 10$ & $<0.05$ \\
$(\mathrm{mV} / 100 \mathrm{ml} / \mathrm{min})$ & $0.42 \pm 0.06$ & $0.40 \pm 0.06$ & $\mathrm{NS}$ \\
rOER & $2.9 \pm 0.3$ & $3.2 \pm 0.3$ & $<0.01$ \\
rCMRO & $4.0 \pm 0.4$ & $4.1 \pm 0.6$ & $\mathrm{NS}$ \\
$(\mathrm{ml} \mathrm{O} / 100 \mathrm{ml} / \mathrm{min})$ & & & \\
rCBV $(\mathrm{ml} / 100 \mathrm{ml})$ & & & \\
\hline
\end{tabular}

NS $=$ Non-significant 
Studies on regional cerebral oxygen utilisation and cognitive function in multiple sclerosis

Table 5 Cerbellar function in multiple sclerosis

\begin{tabular}{llll}
\hline & $\begin{array}{l}\text { Multiple } \\
\text { sclerosis (15) } \\
\text { mean } \pm S D\end{array}$ & $\begin{array}{l}\text { Normals (13) } \\
\text { mean } \pm S D\end{array}$ & p value \\
\hline rCBF & & & \\
$(\mathrm{ml} 100 \mathrm{ml} / \mathrm{min})$ & $41 \pm 8$ & $47 \pm 5$ & $<0.05$ \\
rOER & $0.39 \pm 0.08$ & $0.37 \pm 0.04$ & $\mathrm{NS}$ \\
rCMRO & $2.9 \pm 0.7$ & $3.1 \pm 0.3$ & $\mathrm{NS}$ \\
$(\mathrm{ml} \mathrm{O} / 100 \mathrm{ml} / \mathrm{min})$ & $4.5 \pm 1.4$ & $4.3 \pm 0.7$ & $\mathrm{NS}$ \\
\hline rCBV $(\mathrm{ml} 100 \mathrm{ml})$ & $4.5 \pm$
\end{tabular}

NS $=$ Non-significant

phy group compared to normal controls. Those patients with normal CT scans however had cerebral oxygen utilisation values within the normal range.

Thirteen of the fifteen patients underwent detailed psychometric assessment. The results of

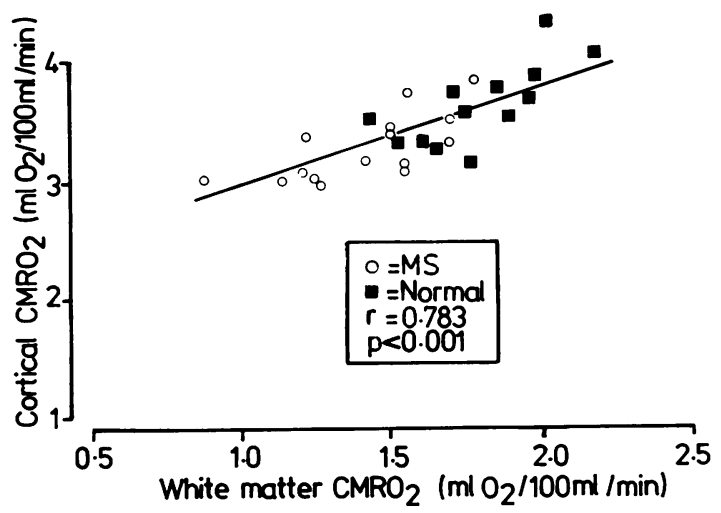

Fig 3 The correlation between cortical and white matter oxygen utilisation in multiple sclerosis patient and normal subject.

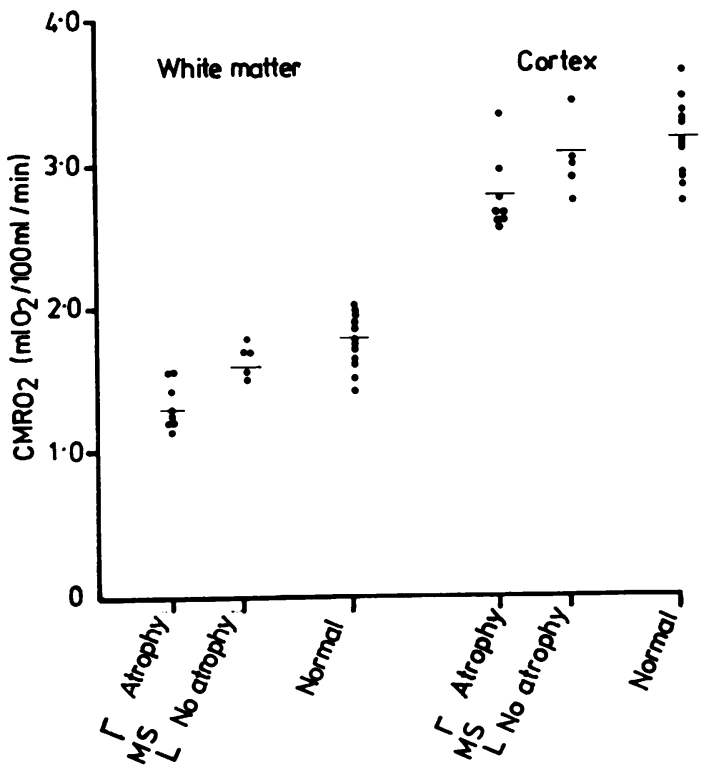

Fig 4 Cerebral atrophy and regional oxygen utilisation in multiple sclerosis.

tests of general cognitive function are detailed in table 6. Mean estimated pre-morbid IQ levels and present full-scale IQ levels for the multiple sclerosis group were not significantly different from normal populations. Using Nelson's.methods of assessment, ${ }^{30} \mathrm{a}$ fall in present full-scale IQ of twelve points or more trom estimated pre-morbid levels is considered pathological. Four of the thirteen patients tested $(31 \%)$ fell into this category and all four had evidence of generalised cerebral atrophy on CT scan

Table 6 General cognitive function in the multiple sclerosis group

\begin{tabular}{|c|c|c|c|c|}
\hline Patient & $\begin{array}{l}\text { Pre-morbid IQ } \\
\text { (NART/Schonell) }\end{array}$ & $\begin{array}{l}\text { Present full-scale IQ } \\
\text { (WAIS) }\end{array}$ & IQ difference & $C T$ scan \\
\hline $\begin{array}{r}5 \\
2 \\
7 \\
11 \\
13 \\
12 \\
3 \\
9 \\
4 \\
8 \\
1 \\
10 \\
6\end{array}$ & $\begin{array}{r}105 \\
114 \\
91 \\
117 \\
119 \\
108 \\
110 \\
119 \\
96 \\
94 \\
121 \\
112 \\
120\end{array}$ & $\begin{array}{r}92 \\
106 \\
98 \\
102 \\
126 \\
88 \\
114 \\
137 \\
79 \\
95 \\
116 \\
105 \\
124\end{array}$ & $\begin{array}{l}-13 \\
-8 \\
+7 \\
-15 \\
+7 \\
-20 \\
+4 \\
+18 \\
-17 \\
+1 \\
-5 \\
-7 \\
+4\end{array}$ & $\begin{array}{l}\text { CSP } \\
\text { C } \\
\text { CS } \\
\text { CSP } \\
\mathbf{N} \\
\text { CSP } \\
\text { CS } \\
N \\
\text { CP } \\
N \\
\text { CS } \\
\frac{N}{N}\end{array}$ \\
\hline Mean & 110 & 106 & & \\
\hline
\end{tabular}

NART: National Adult Reading Test.

Schonell: Schonell Graded Word Reading Test.

CT Scans: $C=$ Generalised central atrophy.

$S=$ Generalised widening of sulci.

$\mathrm{P}=$ Plaques.

$\mathbf{N}=$ Normal 


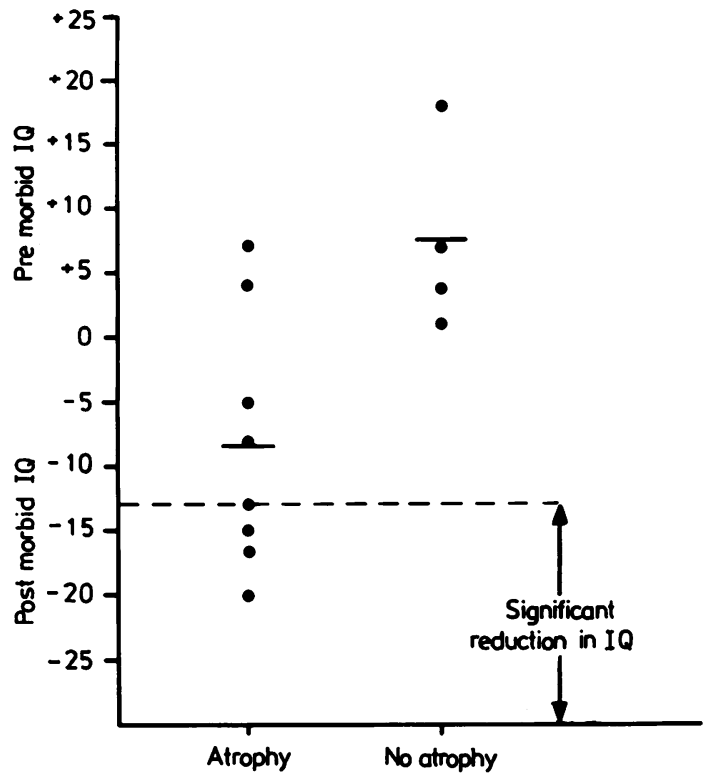

Fig 5 Correlation between pre-and post-morbid IQ change and CT scan atrophy in multiple sclerosis.

(fig 5). When the fall in functional IQ from estimated pre-morbid levels was plotted against mean cortical $\mathrm{rCMRO}_{2}$ values for individual patients, a significant correlation was found (fig 6), those patients with the greatest deterioration in IQ having lowest levels of cortical oxygen utilisation.

Table 7 details the results of psychometric tests of specific cerebral function for thirteen of the patients. Seven of the thirteen patients tested $(54 \%)$ had selective defects in cortical function. Six of these seven patients had current CT brain scans available and all six showed evidence of generalised cerebral atrophy.

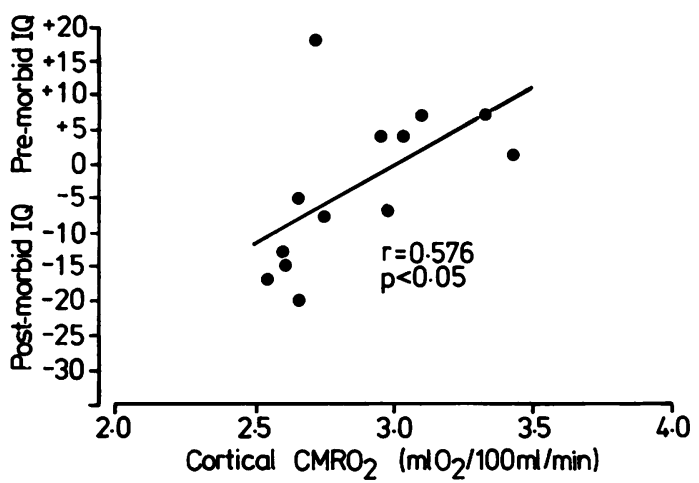

Fig 6 Correlation between cerebral cortical oxgen utilisation and the difference in pre-and post-morbid IQ levels in multiple sclerosis.

Figure 7 shows the relationship between white and peripheral grey matter $\mathrm{rCMRO}_{2}$ values and severity of locomotor dysfunction for individual patients. No significant correlation was found between these quantities, or between levels of cerebral oxygen utilisation and clinical disease duration (fig 8).

\section{Discussion}

The fifteen patients with multiple sclerosis in remission had a lower level of oxygen utilisation by both central white and peripheral cortical grey matter than an age-matched normal control group. The reduction in $\mathrm{rCMRO}_{2}$ was generalised rather than focal and correlated well with the presence of generalised cerebral atrophy on examination of the CT brain scans of the multiple sclerosis group. In individual patients a correlation was found between the depression in levels of mean white and mean peripheral grey matter oxygen utilisation.

Table 7 Tests of specific cortical function in multiple sclerosis

\begin{tabular}{|c|c|c|c|c|}
\hline Patient & $\begin{array}{l}\text { Forced-choice faces } \\
\text { non-dominant temporal }\end{array}$ & $\begin{array}{l}\text { Unusual views } \\
\text { non-dominant parietal }\end{array}$ & $\begin{array}{l}\text { Weigl } \\
\text { frontal }\end{array}$ & $\begin{array}{l}\text { Verbal fuency } \\
\text { frontal }\end{array}$ \\
\hline $\begin{array}{r}5 \\
2 \\
7 \\
11 \\
13 \\
12 \\
3 \\
9 \\
4 \\
8 \\
1 \\
10 \\
6\end{array}$ & $\begin{array}{l}\downarrow \\
\downarrow \\
\mathbf{N} \\
\mathbf{N} \\
\downarrow \\
\mathbf{N} \\
\mathbf{N} \\
\downarrow \\
\mathbf{N} \\
\mathbf{N} \\
\downarrow \\
\mathbf{N}\end{array}$ & $\begin{array}{l}\mathbf{N} \\
\mathbf{N} \\
\downarrow \\
\mathbf{N} \\
\mathbf{N} \\
\mathbf{N} \\
\mathbf{N} \\
\mathbf{N} \\
\mathbf{N} \\
\mathbf{N} \\
\mathbf{N} \\
\mathbf{N} \\
\mathbf{N}\end{array}$ & $\begin{array}{l}\downarrow \\
\mathbf{N} \\
\mathbf{N} \\
\downarrow \\
\mathbf{N} \\
\downarrow \\
\mathbf{N} \\
\mathbf{N} \\
\mathbf{N} \\
\mathbf{N} \\
\mathbf{N} \\
\downarrow \\
\mathbf{N}\end{array}$ & $\begin{array}{l}\downarrow \\
\mathbf{N} \\
\downarrow \\
\mathbf{N} \\
\downarrow \\
\mathbf{N} \\
\mathbf{N} \\
\mathbf{N} \\
\mathbf{N} \\
\mathbf{N} \\
\downarrow \\
\mathbf{N}\end{array}$ \\
\hline
\end{tabular}

$\downarrow=$ deficit. $\mathrm{N}=$ normal.

All patients scored normally on the following tests: forced choice words (dominant temporal); fragmented letters (non-dominant parietal); tapping test (frontal). 


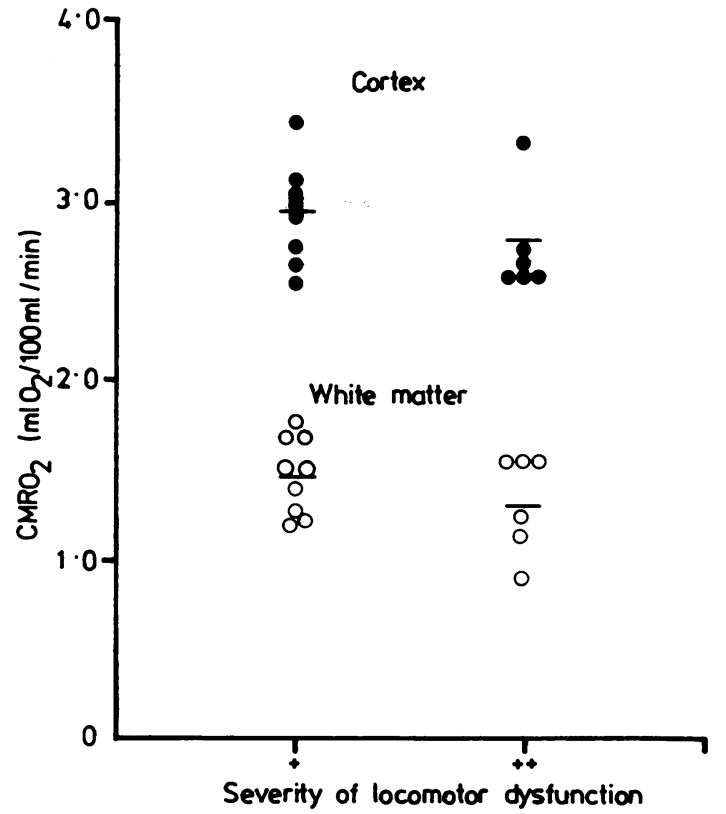

Fig 7 Relationship between regional cerebral oxygen utilisation and severity of locomotor dysfunction in multiple sclerosis.

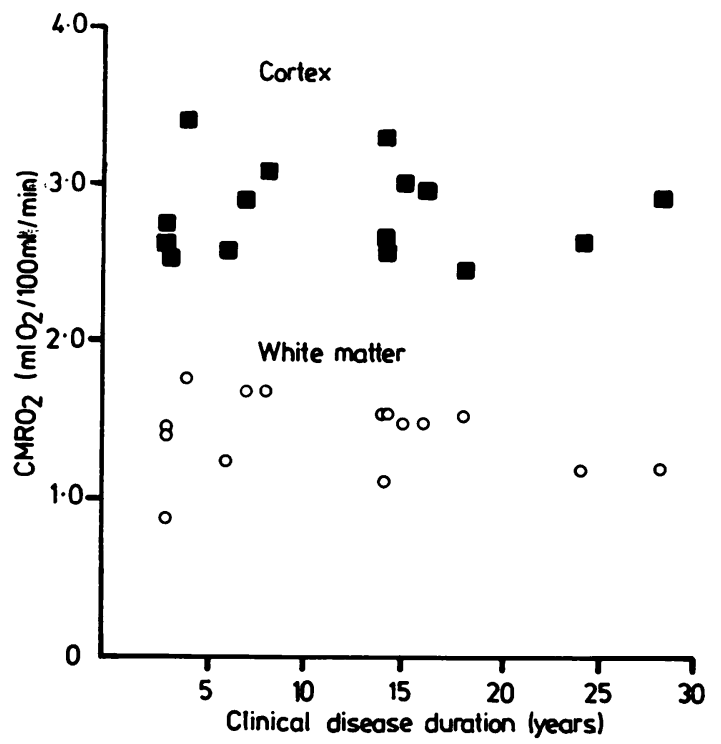

Fig 8 Relationship between regional cerebral oxygen utilisation and clinical disease duration in multiple sclerosis.

This depression in cerebral function found for the multiple sclerosis group as assessed by PET is likely to reflect the volume of increased non-exchanging tissue produced by cerebral atrophy rather than a decrease in actual oxygen utilisation by those neurones still remaining intact. ${ }^{31}$ Cerebral function per unit volume of viable brain tissue, rather than per unit total volume as measured by PET, probably remains similar for both the multiple sclerosis and the normal groups. Mean cortical $\mathrm{rCMRO}_{2}$ was reduced by $9 \%$ from normal values in the multiple sclerosis group as opposed to a $22 \%$ reduction in mean $\mathrm{rCMRO}_{2}$ for white matter. Within the $1.7 \mathrm{~cm}$ resolution of our PET scanner, peripheral cortical grey matter regions of interest contain at least a $50 \%$ contribution from surrounding white matter, the cortical ribbon being only $5 \mathrm{~mm}$ in width. As a result the depression in cortical function found for the multiple sclerosis group could probably be explained entirely in terms of a partial volume effect of the surrounding white matter, where function is more seriously affected. ${ }^{31}$ This is unlikely however to be the sole explanation for the measured cortical hypofunction, as occasionally multiple sclerosis patients are found with evident widening of their sulci on CT brain scans in the absence of central white matter atrophy. ${ }^{\circ}$ Such a CT scan finding implies that cortical atrophy can be a feature of multiple sclerosis in the absence of obvious white matter lesions.

The measurement of regional fractional oxygen extraction by PET is free from problems due to partial volume effects when cerebral atrophy is present, and reflects the oxygen extraction of remaining viable tissue. ${ }^{32}$ This is because the ratios of regional cerebral $\mathrm{H}_{2}{ }^{15} \mathrm{O}$ uptake when ${ }^{15} \mathrm{O}_{2}$ and $\mathrm{C}^{15} \mathrm{O}_{2}$ are inhaled are used to derive rOER values, and so effects of non $\mathrm{H}_{2}{ }^{15} \mathrm{O}$ exchanging regions are eliminated.

The relative sparing of cerebellar oxygen utilisation in the multiple sclerosis group compared to the reduction in central white and peripheral grey matter $\mathrm{rCMRO}_{2}$ is difficult to explain. The cerebellum is a reported site of prediliction for demyelination. ${ }^{1}$ No cerebellar plaques however were evident on the $\mathrm{CT}$ scans of our group of patients.

Eight out of thirteen $(62 \%)$ of the patients had evidence of cerebral atrophy on their CT scans, and in all cases the atrophy was generalised involving either central white matter alone or both central white and peripheral grey matter. Four of the thirteen patients CT scanned had evidence of focal plaques, all four falling into the atrophy group. These data suggest that focal plaques of demyelination, generalised cerebral hypofunction, and generalised cerbral atrophy all form a part of the disease process of multiple sclerosis. In his review of $110 \mathrm{CT}$ brain scans of multiple sclerosis patients, ${ }^{6}$ Gyldensted found a $45 \%$ incidence of generalised cerebral atrophy in the absence of any demonstrable 
focal plaques, supporting this concept, although more plaques may have been demonstrated had NMR rather than CT imaging been used. ${ }^{78}$

Studies of cognitive function in multiple sclerosis also support the concept that cerebral function becomes generally impaired as part of the disease process. In a series of 55 patients, Peyser et $a^{9}$ showed a significant fall in general cognitive function from estimated pre-morbid levels in $55 \%$ of their multiple sclerosis group. In our study, using the NART/Schonell tests to estimate pre-morbid IQ levels, we found a significant deterioration in general cerebral function in $31 \%$ of our multiple sclerosis patients, all of whom had evidence of generalised cerebral atrophy on their CT brain scans. Falls in present IQ from estimated premorbid levels correlated well with present levels of mean cortical oxygen utilisation. Interestingly Frackowiak et al $^{29}$ reported a similar correlation between degree of dementia and levels of cortical $\mathrm{rCMRO}_{2}$ in a group of dementia cases.

Psychometric testing of specific rather than general cerebral functions in our group of patients proved a more sensitive method of detecting cognitive impairment. Seven out of thirteen (54\%) had significant impairment of cognitive function using such tests, as opposed to $31 \%$ when assessment of general IQ was used. Using similar tests Jambor ${ }^{13}$ demonstrated a significant impairment of cognitive function in his group of 103 multiple sclerosis patients. There were no obvious regions of cortical hypofunction or atrophy which corresponded with specific regions of cortical impairment revealed by psychometric testing, all our affected patients having generalised disturbances on PET and CT scanning. It must be remembered however that focal multiple sclerosis plaques may only be $1-2 \mathrm{~mm}$ in length and as such are beyond the resolution of PET and CT scanners currently available.

We found no correlation between levels of cerebral oxygen utilisation and clinical disease duration of multiple sclerosis. Gyldensted ${ }^{6}$ in his series of 110 CT scans was also unable to demonstrate a correlation between degree of cerebral atrophy and clinical disease duration. This finding is surprising and presumably reflects the wide range of disease activity that individual multiple sclerosis patients exhibit on clinical follow-up. Less surprising was the lack of correlation found between levels of cerebral oxygen utilisation and locomotor dysfunction. $\mathrm{rCMRO}_{2}$ values reflect intracerebral disease whereas locomotor dysfunction frequently reflects the presence of brain-stem and spinal cord plaques. Peyser et $a l^{9}$ were also unable to demonstrate any correlation between impairment of cognitive function and degree of neurological impairment.
The low levels of cerebral oxygen utilisation found for our group of multiple sclerosis patients were matched by coupled reductions in cerebral blood flow, mean oxygen extraction by central white and peripheral cortical grey matter in our multiple sclerosis group being similar to that of normal controls. No regions of cerebral tissue with significantly raised oxygen extraction (implying focal tissue ischaemia) were found either in plaques or white matter within the $1.7 \mathrm{~cm}$ resolution of our PET scanner. We were thus unable to find any metabolic grounds for raising the oxygen content of arterial blood supplying the cerebral tissue of multiple sclerosis patients by administering hyperbaric oxygen.

The cause of the generalised cerebral hypofunction and atrophy in multiple sclerosis remains unclear. Numerous submicroscopic plaques leading to Wallerian degeneration of neurons is one possibility. A second possibility is suppression of neuronal activity by a toxic product of myelin breakdown. What is clear is that psychometric evaluation when combined with a conventional neurological examination provides a far more sensitive way of assessing the severity of intracerebral disease than conventional neurological examinations alone, and that levels of cognitive impairment correlate well with the presence of cerebral atrophy and levels of cerbral oxygen utilisation. Ideally multiple sclerosis patients should be reviewed both neurologically and psychometrically, as in this way a truer measure of the extent of the disease is likely to be obtained.

We thank Rowie Jackson and Liz George for their secretarial help in preparing this manuscript, Michelle Almeida and Adam Lewis for technical assistance, and the staff of the MRC Cyclotron Unit for their invaluable help, in particular Drs Jeremy Gibbs, Peter Buckingham and Adriaan Lammertsma.

\section{References}

${ }^{1}$ McAlpine D, Lumsden CE, Acheson ED. Multiple Sclerosis - a Reappraisal. Edinburgh: ChurchillLivingston, 1972.

${ }^{2}$ Charcot JM. Lectures on Diseases of the Nervous System. London: Near Sydenham Society, 1877.

${ }^{3}$ Prineas JW, Wright RE. Macrophages, lymphocytes, and plasma cells in the perivascular compartment in chronic multiple sclerosis. Lab Invest 1978;10:149 58.

${ }^{4}$ Adams RD, Sidman RL. Introduction to Neuropathology. New York: McGraw-Hill, 1968.

${ }^{5}$ Brownell B, Hughes JT. The distribution of plaques in the cerebrum in multiple sclerosis. J Neurol Neurosurg Psychiatry 1962;25:315-20. 
${ }^{\circ}$ Gyldensted C. Computer tomography of the cerebrum in multiple sclerosis. Neuroradiology 1976;12:33-42.

7 Young IR, Hall AS, Pallis CA, Bydder GM, Legg NJ, Steiner RE. Nuclear magnetic resonance imaging of the brain in multiple sclerosis. Lancet 1981;II:1063-6.

${ }^{8}$ Lukes SA, Crooks LE, Aminoff MJ, et al. Nuclear magnetic resonance imaging in multiple sclerosis. Ann Neurol 1983;13:592-601.

9 Peyser JM, Edwards KR, Posser CM, Filskov SB. Cognitive function in patients with multiple sclerosis. Arch Neurol 1980;37:577-9.

${ }^{10}$ Marsh GG. Disability and intellectual function in multiple sclerosis patients. J Nerv Ment Dis 1980; 168: 758-62.

"Canter AH. Direct and indirect measures of psychological deficit in multiple sclerosis. J Gen Psychol 1951;44:3-50.

12 Reiten RM, Reed JC, Dyken M. Cognitive psychomotor and motor correlates of multiple sclerosis.J Nerv Ment Dis 1971;153:218-24.

13 Jambor KL. Cognitive functioning in multiple sclerosis. Br J Psychiatry 1969;115:765-75.

${ }^{14}$ Neubauer RA. Exposure of multiple sclerosis patients to hyperbaric oxygen at 1.5-2 ATA: a preliminary report. J Fla Med Assoc 1980;67:498-504.

${ }^{15}$ Fischer BH, Marks M, Reich T. Hyperbaric oxygen treatment of multiple sclerosis. New Eng J Med 1983;308: 181-6.

${ }^{16}$ Warren JM, Sacksteder MR, Thuning GA. Modification of allergic encephalomyelitis in the guinea pig by oxygen therapy. Fed Proc 1977;36:1298.

${ }^{17}$ Hansborough JF, Piacentine JG, Eiseman B. Immunosuppression by hyperbaric oxygen. Surgery 1980;87:662-7.

${ }^{18}$ Poser CM, Paty DW, Scheinberg L, et al. New Diagnostic Criteria for Multiple Sclerosis: Guidelines for Research Protocols. Ann Neurol 1983:227-31.

19 Wechsler D. Wechsler Adult Intelligence Scale. New York: The Psychological Corporation 1955.

${ }^{20}$ Nelson HE, O' Connell A. Dementia: The estimation of pre-morbid intelligence levels using the new adult reading test. Cortex 1978;14:234-44.
${ }^{21}$ McKenna P, Pratt RTC. The effect of unilateral nondominant ECT on memory and perceptual function. Br J Psychiatry 1983; 142:276-9.

${ }^{22}$ Benton AL. Differential behavoural effects in frontal lobe disease. Neuropsychologia 1968;6:53-60.

${ }^{23}$ Weigl E. On the psychology of so-called processes of abstraction J. Abnorm Soc. Psychol 1941;36:3-33.

${ }^{24}$ Christensen A-L. Luria's Neuropsychological Investigation. Copenhagen: Munksgaard 1979.

${ }^{25}$ Frackowiak RSJ, Lenzi GL, Jones T, Heather JD. Quantitative measurement of regional cerebral blood flow and oxygen metabolism in man using ${ }^{15} 0$ and positron emission tomography. Theory, procedure, and normal values. J Comput Assist Tomogr 1980;4:727-36.

${ }^{26}$ Phelps M, Huang S, Hoffman E, Kuhl D. Validation of the tomographic measurement of cerebral blood volume with C-11 labelled carboxy-haemoglobin.J Nucl Med 1979;20:328-34.

${ }^{27}$ Lammertsma AA, Jones T. Correction for the presence of intravascular oxygen-15 in the steady-state technique for measuring regional oxygen extraction ratio in the brain: 1. Description of the method.J Cereb Blood Flow and Metab 1983;3:416-24.

${ }^{28}$ Wise RJS, Bernardi S, Frackowiak RSJ, Legg NJ, Jones T. Serial observations on the pathophysiology of acute stroke: the transition from ischaemia to infarction as reflected in regional oxygen extraction. Brain 1983;106: 197-222.

${ }^{29}$ Frackowiak RSJ, Pozzilli C, Legg NJ et al. Regional cerebral oxygen supply and utilisation in dementia. Brain 1981;104: 753-78.

${ }^{30}$ Nelson HE. National Adult Reading Test (NART) for the Assessment of Pre-morbid Intelligence in Patients with Dementia. Windsor: NFER-Nelson 1982.

${ }^{31}$ Hoffman EJ, Huang SC, Phelps ME. Quantitation positron emission tomography: 1 . The effect of object size. J Comput Assist Tomogr 1979;3:299-308.

${ }^{32}$ Lammertsma AA, Jones T, Frackowiak RSJ, Lenzi GL. A theoretical study of the steady-state model for measuring regional cerebral blood flow and oxygen utilisation using oxygen-15. J Comput Assist Tomogr 1981;5:544-50. 